\title{
Development of Intensity-Duration-Frequency curves at ungauged sites: risk management under changing climate
}

\author{
San Chuin Liew ${ }^{1 *}$, Srivatsan V Raghavan ${ }^{1}$ and Shie-Yui Liong ${ }^{1,2}$
}

\begin{abstract}
The impact of a changing climate is already being felt on several hydrological systems both on a regional and sub-regional scale of the globe. Southeast Asia is one of the regions strongly affected by climate change. With climate change, one of the anticipated impacts is an increase in the intensity and frequency of extreme rainfall which further increase the region's flood catastrophes, human casualties and economic loss. Optimal mitigation measures can be undertaken only when stormwater systems are designed using rainfall Intensity-Duration-Frequency (IDF) curves derived from a long and good quality rainfall data.

Developing IDF curves for the future climate can be even more challenging especially for ungauged sites. The current practice to derive current climate's IDF curves for ungauged sites is, for example, to 'borrow' or 'interpolate' data from regions of climatologically similar characteristics. Recent measures to derive IDF curves for present climate was performed by extracting rainfall data from a high spatial resolution Regional Climate Model driven by ERA-40 reanalysis dataset. This approach has been demonstrated on an ungauged site (Java, Indonesia) and the results were quite promising.

In this paper, the authors extend the application of the approach to other ungauged sites particularly in Peninsular Malaysia. The results of the study undoubtedly have significance contribution in terms of local and regional hydrology (Malaysia and Southeast Asian countries). The anticipated impacts of climate change especially increase in rainfall intensity and its frequency appreciates the derivation of future IDF curves in this study. It also provides policy makers better information on the adequacy of storm drainage design, for the current climate at the ungauged sites, and the adequacy of the existing storm drainage to cope with the impacts of climate change.
\end{abstract}

Keywords: Climate change; Reanalysis data; Regional climate model; Ungauged sites; IDF curves

\section{Background}

Lack of sufficiently long and good quality rainfall records is common in most Southeast Asian countries or developing countries. This leads to improper designs of urban drainages and stormwater infrastructure systems.

For the past twenty years, the development in analyzing rainfall data for ungauged sites focused on the identification of homogenous regions. Several researchers (e.g. [1,2]) have developed methods for determining homogenous regions characterized by the same statistical distribution. Mikkelsen et al. [3], for example, selected the regional historical

\footnotetext{
* Correspondence: tmsliew@nus.edu.sg

${ }^{1}$ Tropical Marine Science Institute, National University of Singapore, Singapore 119227, Singapore

Full list of author information is available at the end of the article
}

rainfall time series as input to urban drainage simulations at ungauged locations. The results showed that (1) extreme rainfall is often very different even for minor physiographic differences, (2) the uncertainty related to the use of point rainfall data at ungauged locations where no regional model of extreme rainfall properties is available, is generally underestimated. Nguyen et al. [4] proposed regional frequency analysis method for sites where rainfall records are limited or unavailable. In the study, a homogeneous region was defined as the region in which all annual maximum rainfall series at different sites must have similar properties of rainfall occurrence within a given concurrent time period. If the occurrence of rainfalls at different rain gauges within a given concurrent period is similar (e.g. high correlation of the 


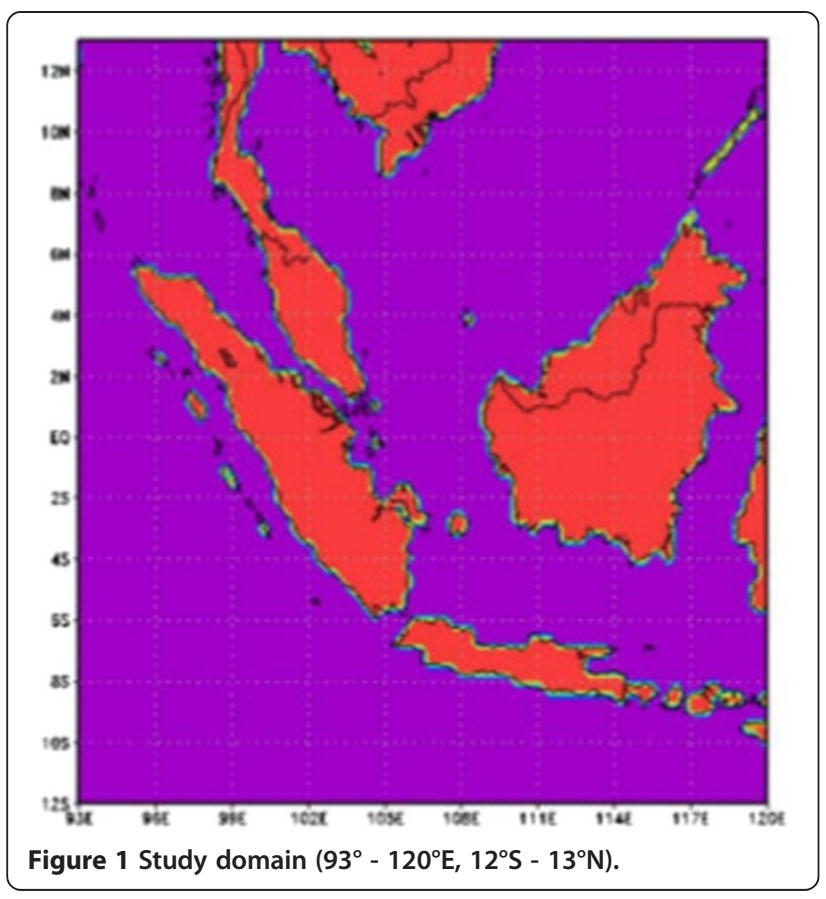

numbers of rainy hours within a given one-day interval), these gauges are thus considered as members of a homogeneous group. Principal component analysis (PCA) is performed using the series number of rainy hours observed at each rain gauge in order to assess the similarity of rainfall occurrences between these gauges. A case study is carried out using annual maximum rainfall series (AMS) from a network of 10 rain gauges in Quebec (Canada). To assess the scaling behaviour of these AMS, the log-log plots of the first three rainfall non-central moments (hereafter, $\mathrm{NCMs}$ ) against duration are prepared for all 10 stations. This study demonstrated that regional frequency analysis, which uses data from many sites, has been shown to be able to reduce the uncertainties in the estimation of extreme events. However, one of the main difficulties in the use of this technique is related to the definition of "homogeneous" regions. Past approaches which mainly focused on identification of homogenous rainfall zones often indicated uncertainty related to homogeneity assumptions of gauged and ungauged regions. Various methods have been proposed for determining the homogeneous regions, but there is no generally accepted procedure in engineering practice.

Lin and Wu [5] performed Self-Organizing Map (SOM) approach to estimate the design hyetograph for ungauged sites. SOM, which is a special kind of artificial neural networks (ANNs), is a powerful technique for extracting and visualizing salient features of data and for solving classification problems. The results show that the proposed approach performs better than methods based on conventional clustering techniques.

Lin et al. [6] has successfully developed AdaptiveNetwork-based Fuzzy Inference System (ANFIS) to forecast a long-term discharges in Manwan Hydropower. The process of fuzzy inference involves membership functions, fuzzy logic operators, and if-then rules. This system has been successfully applied in fields such as automatic control, data classification, decision analysis and computer vision. The results, when compared to the ANN model, the ANFIS model has shown a significant forecast improvement. It showed that the model is an effective algorithm to forecast the long-term discharge in Manwan Hydropower. Several comparison studies were done by Chau et al. [7] and Wu et al. [8] on different types of data-driven models. The results showed that different model may need different computational time as well as additional modeling parameters.

El-Sayed [9] used isopluvial map approach to develop rainfall IDF curves for ungauged sites. The author first obtained the maximum annual precipitation series at each station for different durations, fitted with General Extreme value (GEV), and determined the value of each of the 3

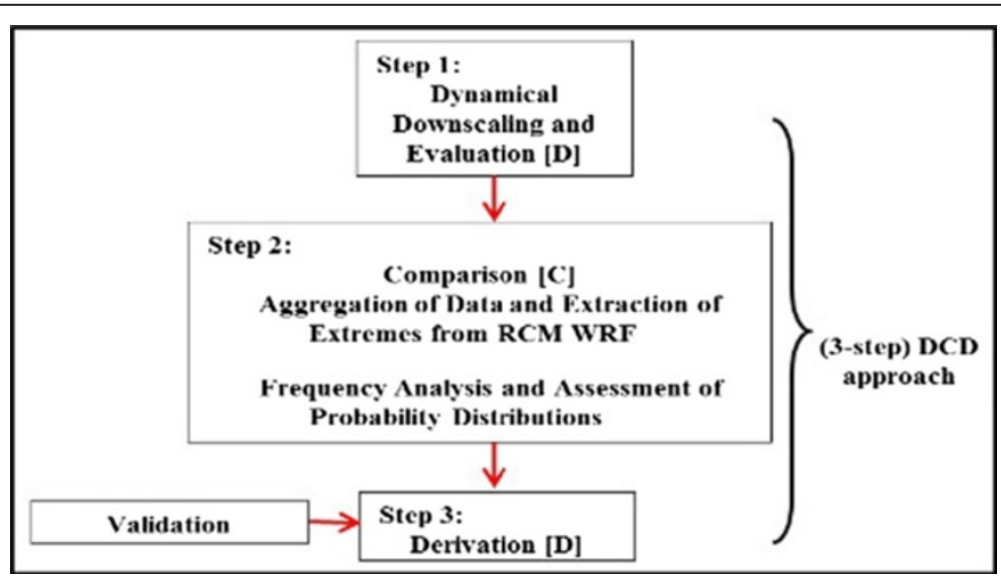

Figure 2 (3-step) DCD approach to develop IDF curves regions with short or no rainfall data. 


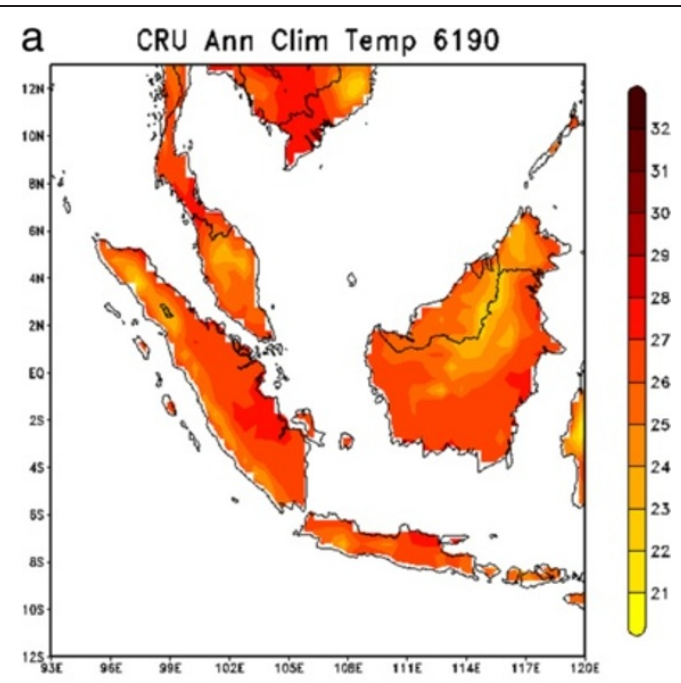

\section{b wrfot_era Ann Clim Temp 6190}

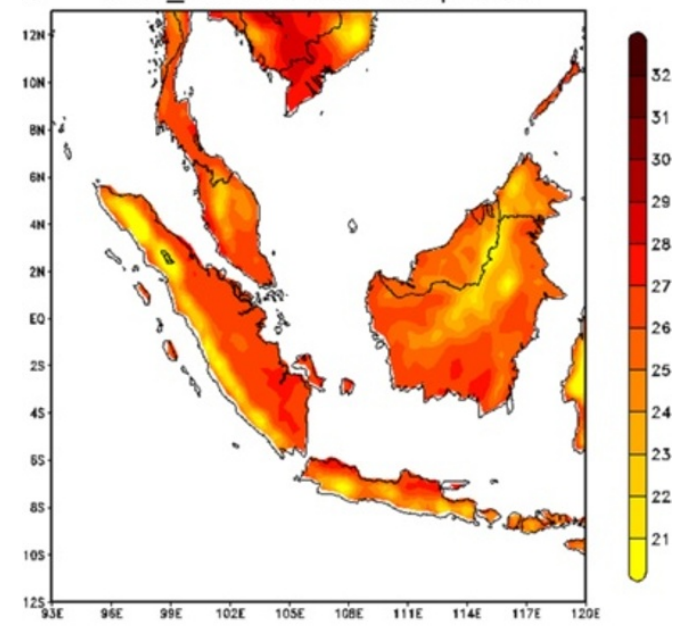

\section{C wrfot_ccsm Ann Clim Temp 6190}

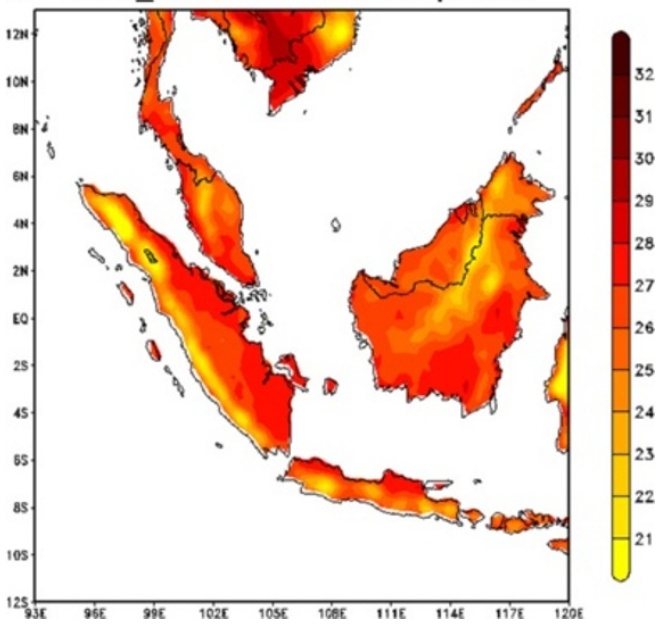

Figure 3 Mean annual air temperature (T2), o $\mathrm{C}, 1961-1990$ (a) CRU (b) WRF/ERA40 (c) WRF/CCSM.
GEV parameters to find depth-duration-frequency (DDF) values for different return periods. From these parameters, isopluvial maps were generated. The DDF values were then spatially interpolated to obtain isopluvial maps for all durations and return periods. The parameter contour maps were used to estimate the 3-parameters GEV of ungauged sites.

All past works have successfully obtained rainfall data for ungauged sites within the homogenous regions. However, the approaches fail for sites which lie outside the area of gauged sites. Recently Liew et al. [10] presented an approach to overcome it. The approach derives IDF curves, for present climate, with rainfall data extracted from a high spatial resolution Regional Climate Model driven by ERA-40 Reanalysis dataset. This approach was demonstrated on an ungauged site (Java, Indonesia); the results were quite promising. The proofof-concept analyses showed that the IDF curves derived from Weather Research and Forecasting Model (WRF) driven by ERA40 fairly consistently underestimate each existing IDF curves ranging from $38 \%$ to $45 \%$. The range of the bias correction showed reasonable results when applied to and compared with a validation site in Jakarta. Liew et al. [10] also employed the RCM WRF to generate climate projection for the studied domain and then derived future climate's IDF curves. The emission scenario A2 and Global Climate Model/European Centre Hamburg Model (GCM/ECHAM5) were used in the study.

In this paper, the authors extend the applications of the aforementioned approach to other ungauged sites in the Peninsular Malaysia. The study is performed by first identifying the nearest meteorological stations where IDF curves exist. Biases resulting from these meteorological sites are captured and serve as very useful information in the derivation of present day IDF curves for ungauged sites. The present day climate's derived IDF curves at the ungauged sites fall within the suggested bias correction range. This range allows designers to decide on a value within the lower and upper bounds, normally subjected to engineering, economic, social and environmental concerns. Approach discussed in this study presents policy makers better information on the adequacy of storm drainage design, for the current climate, at the ungauged sites as well as the adequacy of the existing storm drainage to cope the impacts of climate change.

The Peninsular Malaysia has approximately a total area of $131,000 \mathrm{~km}^{2}$ and consists of rugged forested mountainous interiors descending to coastal plains. The climate is hot and humid with rainfall experienced throughout the year, between 150 and 200 wet days and an annual amount of 2000-4000 mm. The seasonal wind flow patterns coupled with the local topographic features determine the rainfall distribution patterns over the country. During the northeast monsoon season, the exposed 


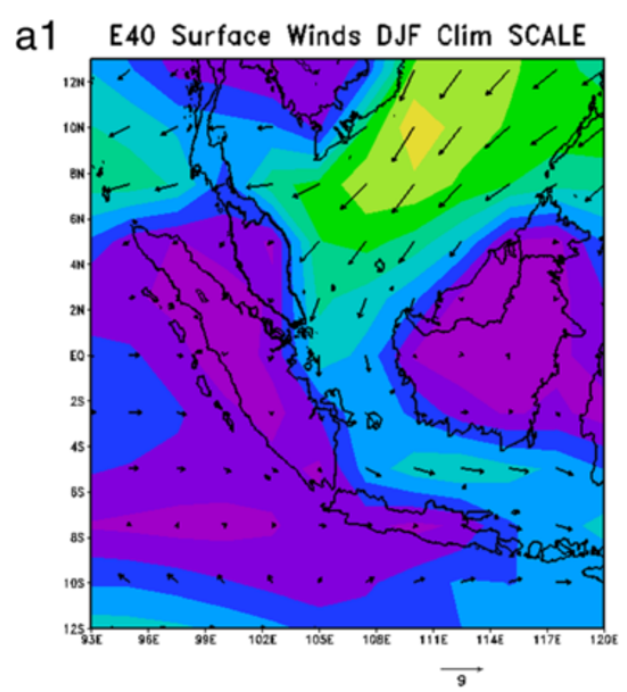

b1 WRF_ERA Surface Winds DJF Clim SCALE

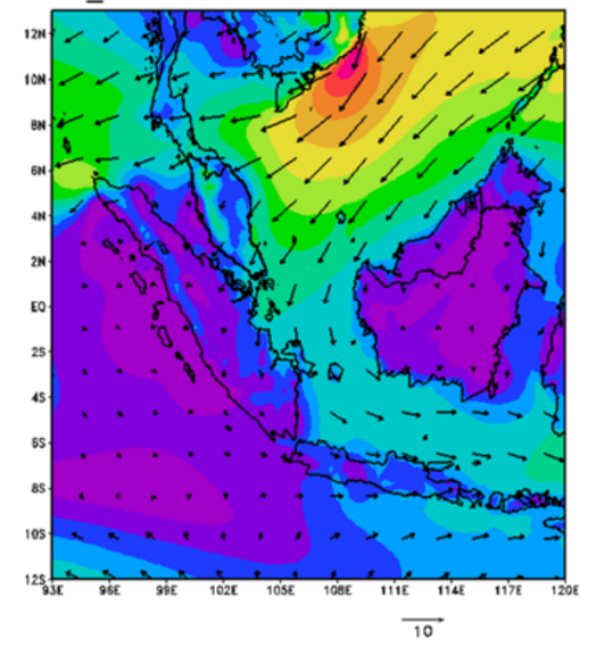

C1 WRF_CCSM Surface Winds DJF Clim SCALE

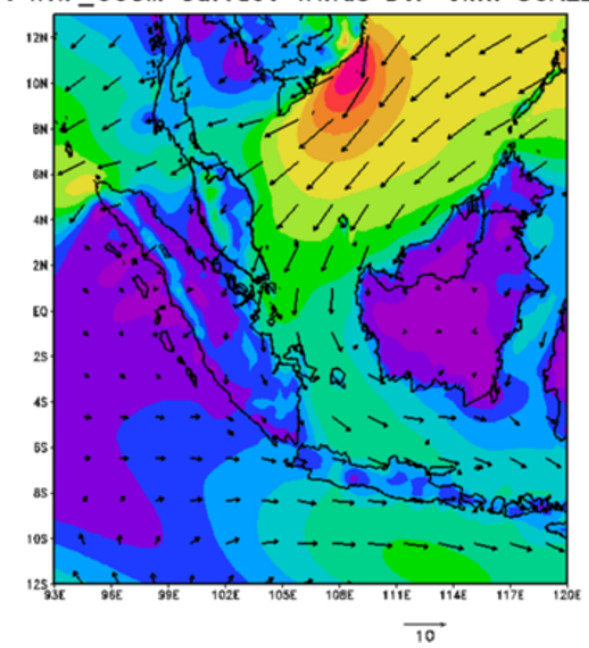

a2

E40 Surfoce Winds JJA Clim SCALE

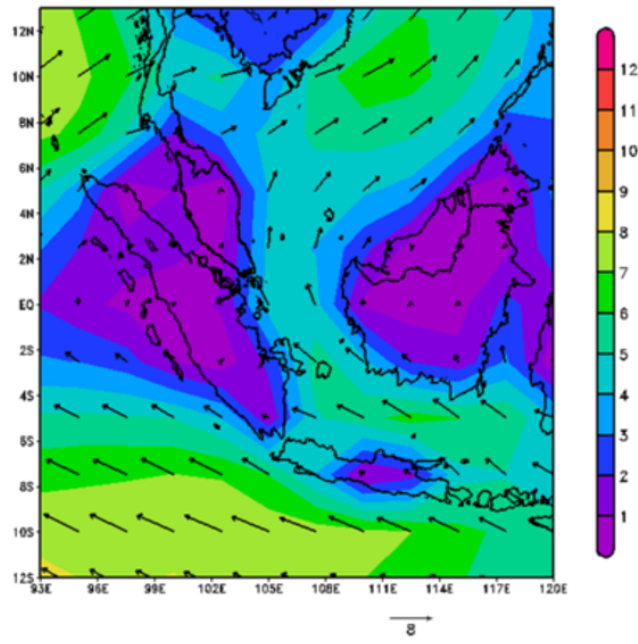

b2 WRF_ERA Surface Winds JJA Clim SCALE

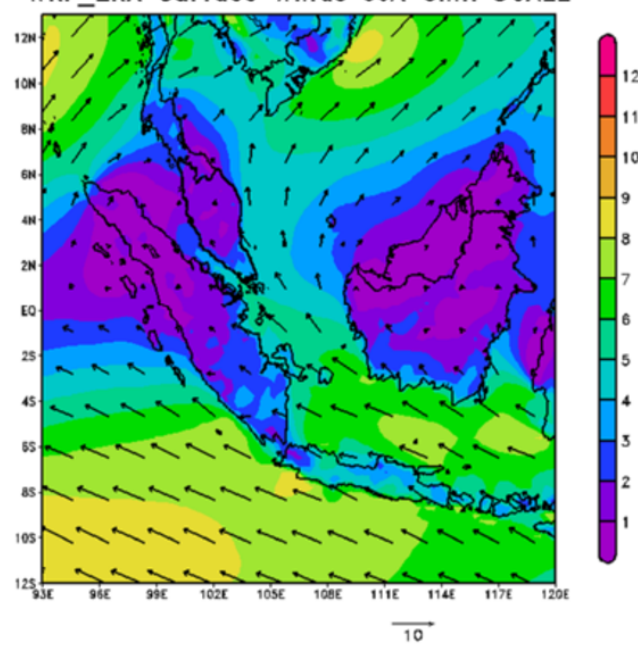

C2 WRF_CCSM Surface Winds JJA Clim SCALE

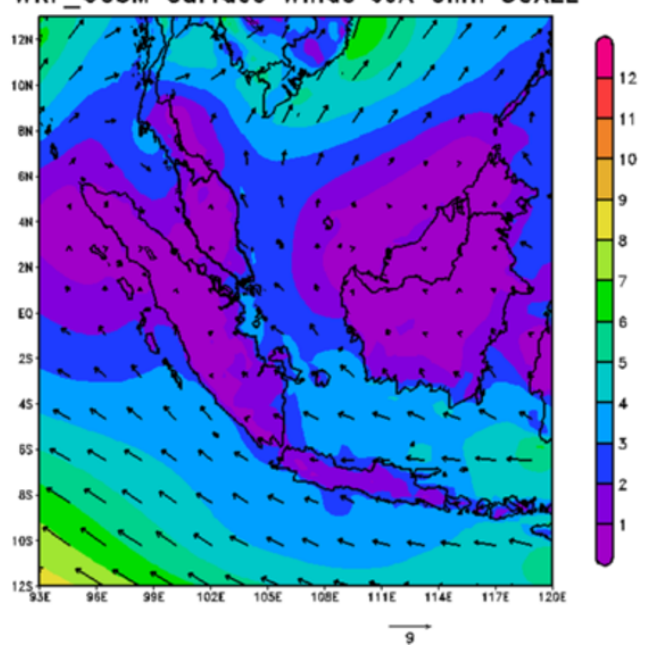

Figure 4 Mean seasonal Northeast Monsoon (NDJF, left panel) and Southwest Monsoon (JJA, right panel) surface winds, m/s, 1961-1990 (a) ERA40 (b) WRF/ERA40 (c) WRF/CCSM. 


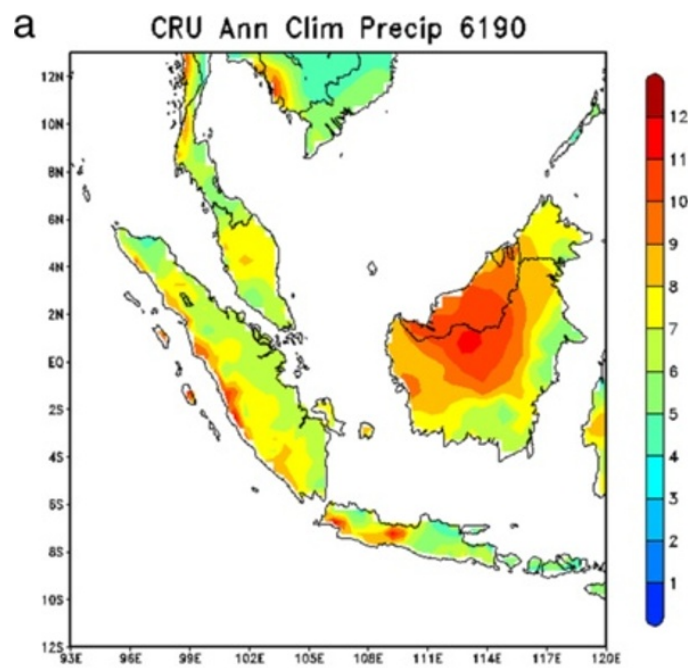

b wrfot_era Ann Clim Precip 6190

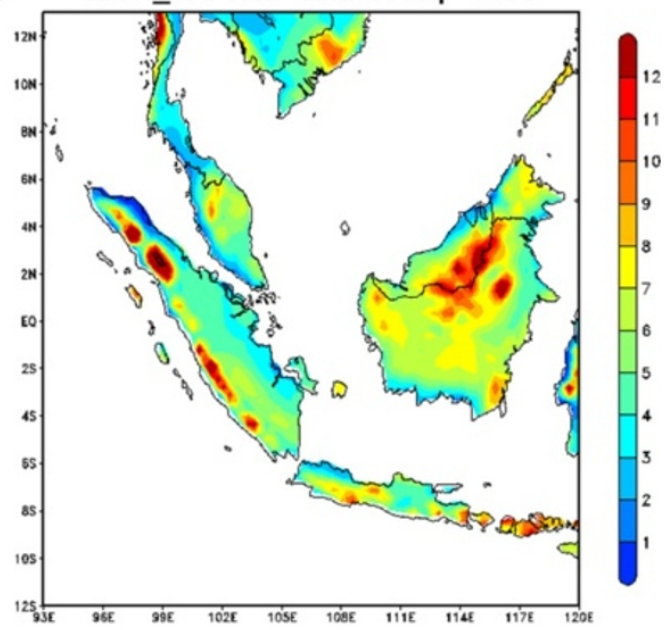

C

C wrfot_ccsm Ann Clim Precip 6190

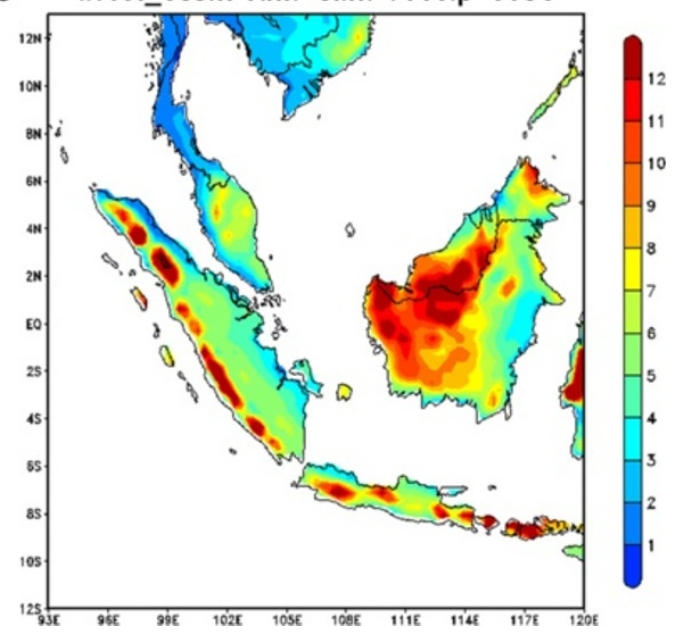

Figure 5 Mean annual precipitation (mm/day), 1961-1990 (a) CRU (b) WRF/ERA40 (c) WRF/CCSM. areas like the east coast of Peninsular Malaysia experience heavy rain spells. On the other hand, inland areas or areas which are sheltered by mountain ranges are relatively free from its influence. The Peninsular Malaysia was seriously hit with heavy floods between December 2006 and January 2007. The floods were caused by above average rainfall. With changing climate, it is of serious concern to investigate whether Peninsular Malaysia will experience even more intense rainfall. Should the intensity of the projected rainfall significantly increase, it is imperative to derive future IDF curves to check the adequacy of the current drainage designs.

\section{Model, data and methodology Model}

Weather Research and Forecasting Model (WRF)

WRF, used in this study, is a regional climate model developed at the National Center for Atmospheric Research (NCAR) in the USA. It is suitable for a broad spectrum of applications across scales ranging from meters to thousands of kilometres. The WRF model (http://www.wrf-model.org) also contains a multitude of physical parameterizations and supports high resolution climate simulations. Due to its sophisticated model physics and its capability to be tuned to user needs, this model not only finds wide application in real time Numerical Weather Prediction (NWP), but also in climate research, where the model can be run for long term climate simulations.

\section{Data}

\section{The ERA-40 reanalysis}

The ERA-40 reanalysis, developed by the European Centre for Medium range Weather Forecasts [11], provide information about a suite climate variable (e.g. precipitation, humidity, temperature and pressure) every six hours, at a horizontal resolution of $2.5^{\circ} \times 2.5^{\circ}$. The ERA40 reanalysis products (http://www.ecmwf.int/research/era/) use a global spectral grid model and assimilate part of the observational data from a wide variety of observed sources.

\section{Climatic Research Unit}

Developed at the Climatic Research Unit (CRU; University of East Anglia, UK), the CRU TS version 3.0 (http:// www.cru.uea.ac.uk/cru/) dataset is used in this study. It comprises monthly grids of observed climate, for the period 1901-2006 covering only the global land surface at $0.5^{\circ} \times 0.5^{\circ}$ horizontal spatial resolution. Precipitation and Temperature variables from the simulations of the WRF are compared against this data over the period of 1961-1990. 


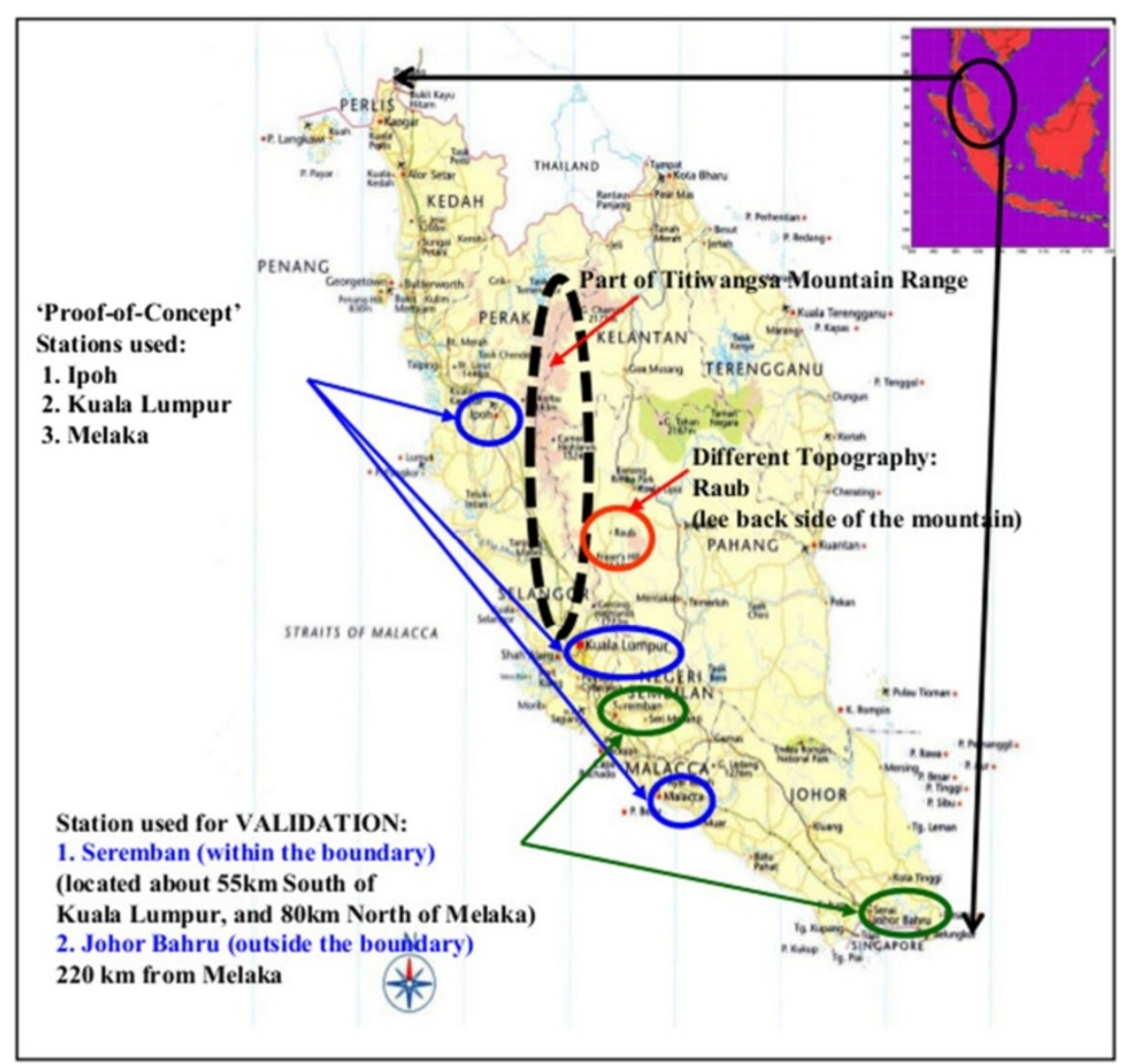

Figure 6 Location of rainfall stations in the study; Peninsula Malaysia.

\section{Community climate system model}

The components of Community Climate System Model (CCSM) include an atmospheric model (Community Atmosphere Model), a land-surface model (Community Land Model), an ocean model (Parallel Ocean Program), and a sea ice model (Community Sea Ice Model). The atmospheric component of CCSM is the Community Atmosphere Model which has a $256 \times 128$ regular longitude/latitude global horizontal grid (giving a $1.4^{\circ} \times 1.4^{\circ}$ resolution). A detailed description of the model is given in Collins et al. [12].

Table 1 Distance $(\mathrm{km})$ of rainfall stations applied in the study: Peninsula Malaysia

\begin{tabular}{lccccc}
\hline $\begin{array}{l}\text { Distance in } \\
\text { kilometers (km) } \\
\text { (approximation) }\end{array}$ & Ipoh & $\begin{array}{c}\text { Kuala } \\
\text { Lumpur }\end{array}$ & Seremban Melaka & $\begin{array}{l}\text { Johor Raub } \\
\text { Bahru }\end{array}$ \\
\hline Ipoh & & & & & \\
Kuala Lumpur & 200 & & & & \\
Seremban & 270 & 155 & & & \\
Melaka & 350 & 120 & 80 & 220 & \\
Johor Bahru & 570 & 370 & 300 & 229 & 333 \\
Raub & 153 & 72 & 118 & 229 & \\
\hline
\end{tabular}

\section{Methodology}

Dynamical downscaling

In this study, the dynamical downscaling is performed over the Southeast Asia region. The WRF was driven at a $30 \times 30 \mathrm{~km}$ resolution by ERA-40 Global Reanalysis for current climate as well as under the A2 greenhouse gas emission scenario for the future climate. The domain considered in this study is $93^{\circ} \mathrm{E}-120^{\circ} \mathrm{E}, 12^{\circ} \mathrm{S}-13^{\circ} \mathrm{N}$ (Figure 1 ).

\section{Extraction of extremes rainfall and probability} distribution function

The present day's 6-hourly precipitation datasets at 3 gauged sites (Figure 1; Ipoh, Kuala Lumpur and Melaka

Table 2 Percentage difference between existing and WRF/ERA40 derived IDF curves: Ipoh Station

\begin{tabular}{lccccccc}
\hline Ipoh station (1961-1990) & $\begin{array}{c}\text { Duration } \\
\text { (Min) }\end{array}$ & \multicolumn{5}{c}{ Return period (year) } \\
\cline { 3 - 8 } & $\mathbf{2}$ & $\mathbf{5}$ & $\mathbf{1 0}$ & $\mathbf{2 0}$ & $\mathbf{5 0}$ & $\mathbf{1 0 0}$ \\
\hline$\left[(\mathrm{IDF})_{\text {Existing }}-(\mathrm{IDF})_{\text {WRF/ERA40 }}\right] /$ & 360 & 60 & 51 & 47 & 44 & 41 & 41 \\
$\left.(\mathrm{IDF})_{\text {Existing }} \%\right)$ & 720 & 48 & 40 & 39 & 37 & 34 & 35 \\
& 1080 & 46 & 38 & 37 & 35 & 32 & 32 \\
& 1440 & 42 & 35 & 36 & 35 & 34 & 34 \\
Average\%-age difference & & 49 & 41 & 40 & 38 & 35 & 41 \\
\hline
\end{tabular}


Table 3 Percentage difference between existing and WRF/ERA40 derived IDF curves: Kuala Lumpur station

\begin{tabular}{|c|c|c|c|c|c|c|c|}
\hline \multirow[t]{2}{*}{ Kuala Lumpur (1961-1990) } & \multirow{2}{*}{$\begin{array}{l}\text { Duration } \\
\text { (Min) }\end{array}$} & \multicolumn{6}{|c|}{ Return period (year) } \\
\hline & & 2 & 5 & 10 & 20 & 50 & 100 \\
\hline \multirow{4}{*}{$\begin{array}{l}(\text { IDF) } \\
\left.\text { Existing }-(\text { IDF) })_{\text {WRF/ERA40 }}\right] / \\
(\text { IDF) } \\
\text { Existing }\end{array}$} & 360 & 69 & 59 & 53 & 47 & 38 & 31 \\
\hline & 720 & 61 & 50 & 46 & 39 & 27 & 17 \\
\hline & 1080 & 56 & 47 & 44 & 40 & 30 & 20 \\
\hline & 1440 & 50 & 43 & 43 & 41 & 34 & 26 \\
\hline Average\%-age difference & & 59 & 50 & 47 & 42 & 32 & 24 \\
\hline
\end{tabular}

Stations) were first extracted from the WRF/ERA40 (WRF model driven by ERA40), for the period 19611990. Data aggregation is based on selected design storm durations $(6,12,18$ and 24 hours). After the aggregation of the selected storm duration data, the identification of the extreme events (annual maximum) was performed. For the 6-hourly rainfall duration study, a total of 30 annual maximum rainfall depths (1961-1990) were then extracted from the 6-hourly rainfall data. The same processes were repeated for 12,18 and 24 hour rainfall duration from their respective precipitation datasets. The GEV distribution was adopted in this study. Method of L-moments [13] was used to determine the GEV's three distribution parameters.

\section{Derivation of IDF curves for ungauged sites}

A 3-step approach; Step 1: Dynamical Downscaling [D]; Step 2: Comparison [C], and Step 3: Derivation of IDF curves [D] which is also known as 3-step DCD approach [10] , Figure 2, is used in this paper to develop IntensityDuration-Frequency (IDF) curves at ungauged sites. These 3 steps in the DCD approach are detailed below.

\section{Step 1: Dynamical Downscaling and Performance Evaluations}

Dynamical downscaling was first performed to obtain high resolution climate outputs. Firstly, the performance evaluation of WRF/ERA40, for the study region at $30 \times$ $30 \mathrm{~km}$ spatial resolution was done by comparing the simulation results with the CRU gridded observation data. Later, the GCM CCSM3.0 was downscaled for both the present day (1961-1990) and future climates (2071-

Table 4 Percentage difference between existing and WRF/ERA40 derived IDF curves: Melaka station

\begin{tabular}{lccccccc}
\hline Melaka station (1961-1990) & $\begin{array}{c}\text { Duration } \\
\text { (Min) }\end{array}$ & \multicolumn{6}{c}{ Return period (year) } \\
\cline { 3 - 8 } & & $\mathbf{2}$ & $\mathbf{5}$ & $\mathbf{1 0}$ & $\mathbf{2 0}$ & $\mathbf{5 0}$ & $\mathbf{1 0 0}$ \\
\hline [(IDF) ${\text { Existing }-(\text { IDF) })_{\text {WRF/ERA40] }} /}$ & 360 & 56 & 53 & 52 & 52 & 50 & 51 \\
(IDF) Existing (\%) & 720 & 48 & 44 & 42 & 43 & 39 & 40 \\
& 1080 & 50 & 45 & 42 & 43 & 40 & 41 \\
& 1440 & 49 & 43 & 39 & 41 & 39 & 39 \\
Average\%-age difference & & 51 & 46 & 44 & 45 & 42 & 46 \\
\hline
\end{tabular}

2100). Figure 3 shows surface air temperature distributions, over the domain region, from CRU, WRF/ERA40 and WRF/CCSM3.0. The simulation results compared well with that of CRU for the entire domain. As there are no observation data (e.g. CRU) available for land and ocean and as there are no surface winds available from the actual GCM CCSM3.0, it has not been possible to include them in the figures for comparison. Thus, the simulated surface winds were compared with ERA40 reanalysis data, WRF/ERA40 and WRF/CCSM itself (Figure 4). The comparisons were done for both monsoon seasons (northeast, NDJF, and southwest, JJA). As shown in Figure 5, overall simulated mean daily precipitation of WRF/ERA40 and WRF/CCSM compared reasonably well with CRU, aside from WRF/CCSM slightly underestimates rainfall in some regions of the northern domain compared to both WRF/ERA40 and CRU. However, the spatial distributions of rainfall of WRF/CCSM over the regions of Malaysian Peninsular and Sumatra, Indonesia show reasonably good agreement against WRF/ERA40.

\section{Step 2: WRF/ERA40 vs gauge data derived IDF curves}

The annual maximum series resulting from the 6-hourly WRF/ERA40 simulation were used in the development of IDF curves. To generate annual maximum series, rainfall data aggregation followed by determination of a suitable probability distribution function for annual maximum rainfall was performed. Since the main objective of this study is to develop IDF curves for locations at which IDF curves are not available, the analyses was first done on locations at which reliable IDF curves are available. Three metrological stations (Figure 6 and Table 1) with IDF curves are Ipoh, Kuala Lumpur and Melaka Station. Their IDF curves were used for comparison with the IDF curves derived from WRF/ERA40 data and the required bias correction measures for each station were noted. The bias correction quantity is used later for deriving IDF curves at ungauged sites [10]. The idea here is to assess how much the WRF/ERA40 derived IDF curves deviate from observations. The baseline period over the present day climate considered was 19611990. The percentage differences between both IDF curves (Existing vs. WRF/ERA40 derived IDF curves) are computed and the upper and lower bounds (i.e. range of bias correction) from the three stations were recorded. These were done for 2, 5, 10, 20, 50 and 100 year return periods.

Tables 2, 3 and 4 show consistent underestimation of WRF/ERA40 derived IDF. It ranges from 40\% - 46\%; these form the lower and upper bounds of the bias correction (Figure 7) of the present day's IDF curves derived from WRF/ERA40.

Step 3: derivation of IDF curves for ungauged sites Three stations, Seremban (within region), located about $55 \mathrm{~km}$ south of Kuala Lumpur Station and Johor Bahru 


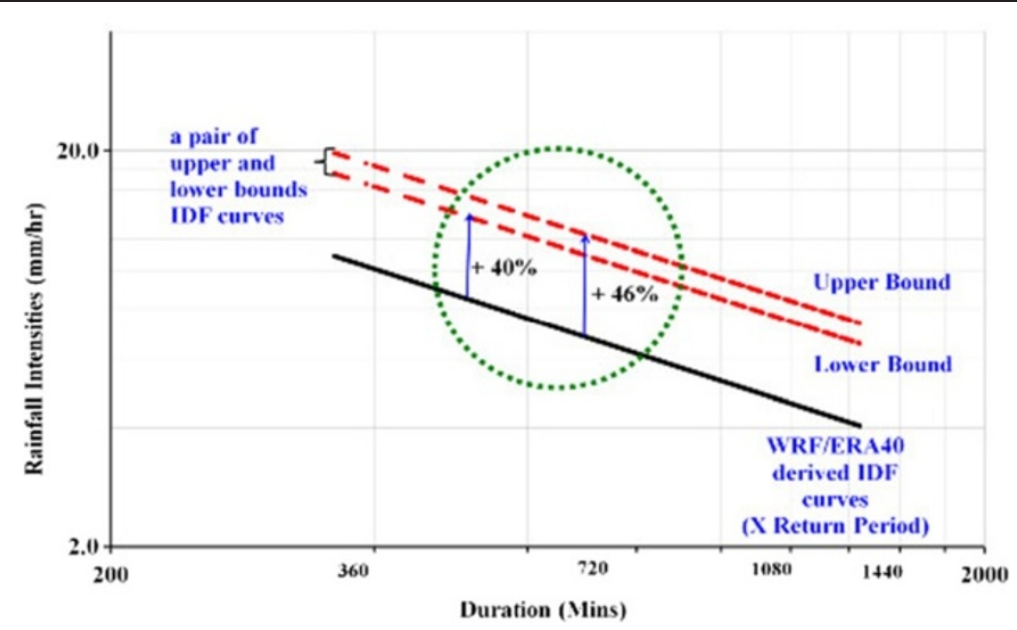

Figure 7 Bias correction on the present day's IDF curves derived from WRF/ERA40: lower and upper bounds.

(outside region), located $220 \mathrm{~km}$ from Melaka Station and Raub (lee back side of Titiwangsa mountain range) were selected as ungauged sites, thus, they are used as validation sites (Figure 6 and Table 1). Note that Seremban, Johor Bahru and Raub stations have raingauge data derived IDF curves; however, they are used here to demonstrate the performance of the proposed. The existing IDF curves for both Seremban and Johor Bahru stations are compared with the upper and lower bounds (range of bias correction) obtained from the 3 aforementioned locations.

IDF curves for both Seremban and Johor Bahru Stations was first derived from rainfall data simulated by WRF/ ERA40. The lower $(+40 \%)$ and upper $(+46 \%)$ bounds (range of bias correction) obtained from Step 2 was assumed to be applicable to the region, such as Seremban and Johor Bahru Station. Figures 8 and 9 compare the upper and lower WRF/ERA40 derived IDF curves with the existing IDF curves of Seremban and Johor Bahru stations respectively. It can be seen that the existing IDF curve for 10-year return period mainly lies within the lower and upper bounds resulting from the proposed approach. Due to space limitation, this paper only focused on 10-year return period; however, results show that all the return periods fall within the lower and upper bounds.

It should be noted, however, that although Raub station is located very close to Kuala Lumpur, it is on the lee back side of part of Titiwangsa mountain range (Figure 6). Thus, it is expected that the rainfall characteristics of Raub Station differ from that of Kuala Lumpur. Figure 10 shows that existing IDF curve of Raub Station for 10year return period does not lie within the lower and upper bounds resulting from the proposed approach. The results concluded that the proposed approach is sensitive to topography.

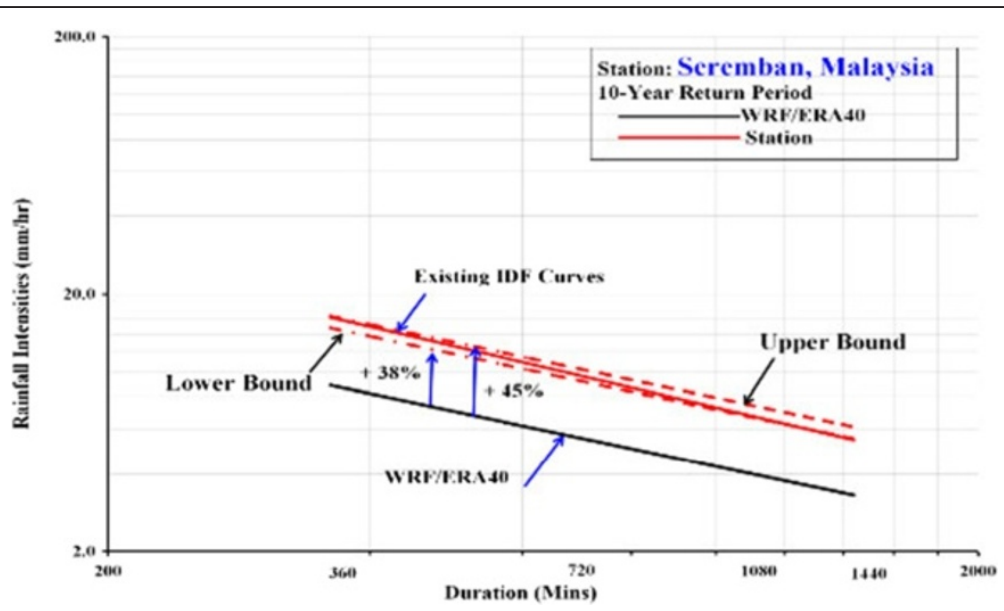

Figure 8 WRF/ERA40 projected present day rainfall intensties anomalies from the existing IDF curve (10-year return period): Seremban station (within region). 


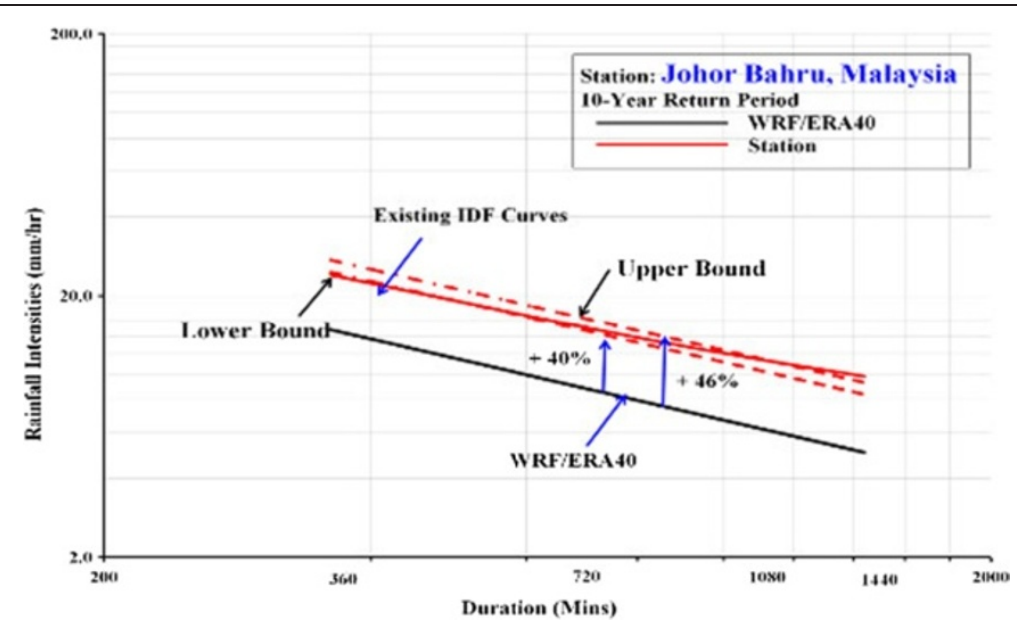

Figure 9 WRF/ERA40 projected present day rainfall intensties anomalies from the existing IDF curve (10-year return period): Johor Bahru station (outside region).

\section{Future IDF curves under changing climate}

Previous sections described the approach, presented in Liew et al. [10], to derive present climate's IDF curves for ungauged sites. For the anticipated changes in rainfall intensities due to climate change, this paper continues to propose the development of future climate IDF curves for ungauged sites. The approach is easier understood when it first be applied to sites with existing IDF curves. In the paper, only time slice of 2071-2100 and the Kuala Lumpur Station are considered for demonstration of the approach. For ungauged sites, this section presents future IDF curves for Seremban (within region) and Johor Bahru (outside region).

Future climate IDF curves for Kuala Lumpur station A simple "delta" (climate change factor, $\Delta \mathrm{i}$ ) method is adopted in this study. The climate change factor refers to 'simulated future rainfall intensities minus present day rainfall intensities' [14], This change is added directly to the existing IDF curves with respect to the return periods. The projected IDF curves for Kuala Lumpur Station are shown in Figure 11. The projected future climate IDF curves for Kuala Lumpur Station shows that simulations of WRF/CCSM A2 demonstrated a high percentage rainfall intensity increase for a 50-year return period, for the 24-hour duration storm, the increase by the year 2100 is about $70 \%$ relative to present day. A 5year return period storm is widely used to design drainage system. The results indicate that the current rainfall intensity $(9 \mathrm{~mm} / \mathrm{hr})$ of a 50 -year return period of 24 hour duration is projected to occur more frequently, 1 in every 5 years by Year 2100. This implies that the current drainage system will not be able to cope with future extreme events.

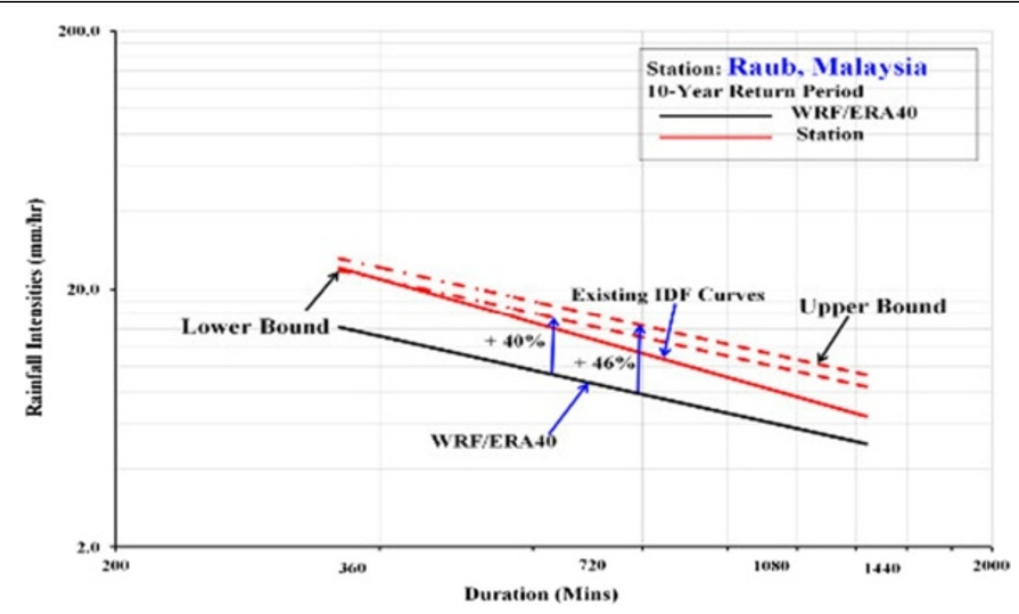

Figure 10 WRF/ERA40 projected present day rainfall intensties anomalies from the existing IDF curve (10-year return period): Johor Raub station (lee back side of the mountain). 


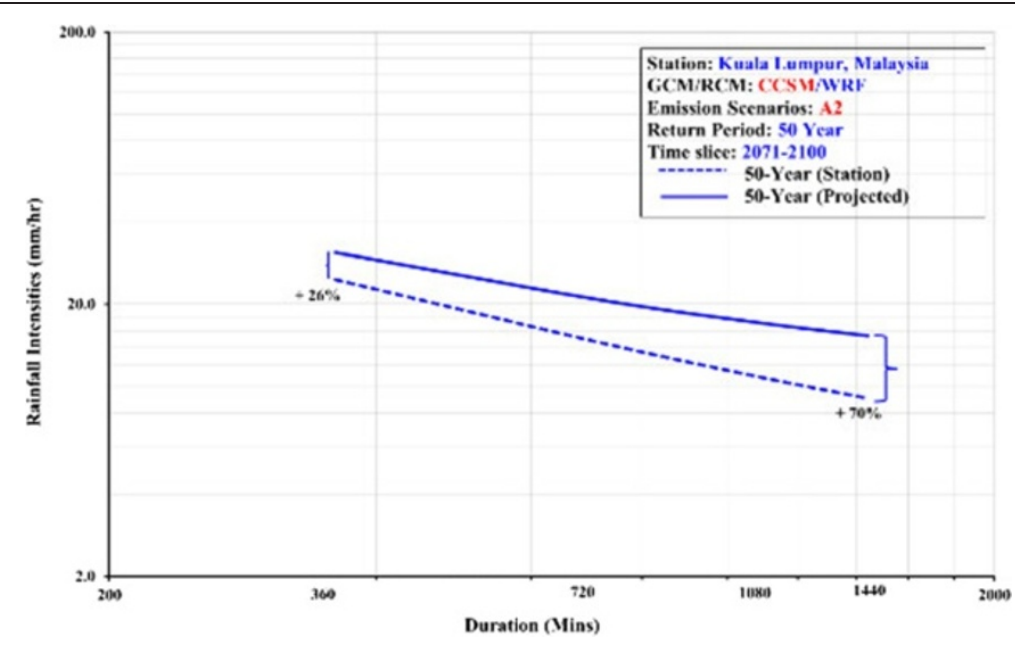

Figure 11 Projected future climate IDF curves (50-year return period, 2071-2100, WRF/CCSM A2 derived): Kuala Lumpur station.

Projected future climate IDF curves for Seremban and Johor stations or ungauged stations

For the development of future climate IDF curves for Seremban and Johor Bahru stations or ungauged stations, the climate change factor $(\Delta \mathrm{i})$ is added to the present day's lower and upper bounds of WRF/ERA40 derived IDF curves to form the range for each of the return periods for future rainfall extremes. For 50-year return period, 2071-2100, Figures 12 and 13 showcase the future upper and lower bounds of Seremban and Johor Bahru station respectively.

\section{Conclusions}

Development of IDF curves is crucial for undertaking short-term measures as well as long-term management and adaptations in water related sectors. This study provides a solution to derive present climate IDF curves for ungauged sites outside the domain of gauged stations in
Peninsular Malaysia. While the approach suggested in Liew et al. [10] is used in this study, the results of the study undoubtedly have significance contribution in terms of local and regional hydrology (Malaysia and Southeast Asian countries). The anticipated impacts of climate change especially increase in rainfall intensity and its frequency appreciates the derivation of future IDF curves in this study. Lower resolution climate simulations may lead to underestimation of present and future rainfall intensities; thus, further research is required to improve the confidence of these results. A larger ensemble of GCMs and even higher resolution RCM simulations might yield enhanced local information that could be used for adaptation. Nevertheless, this study serves to emphasize the usefulness of the approach suggested by Liew et al. [10].

The most interesting part of the study is that the approach strikingly departs from the existing approaches; the approach uses projected rainfall data resulting from

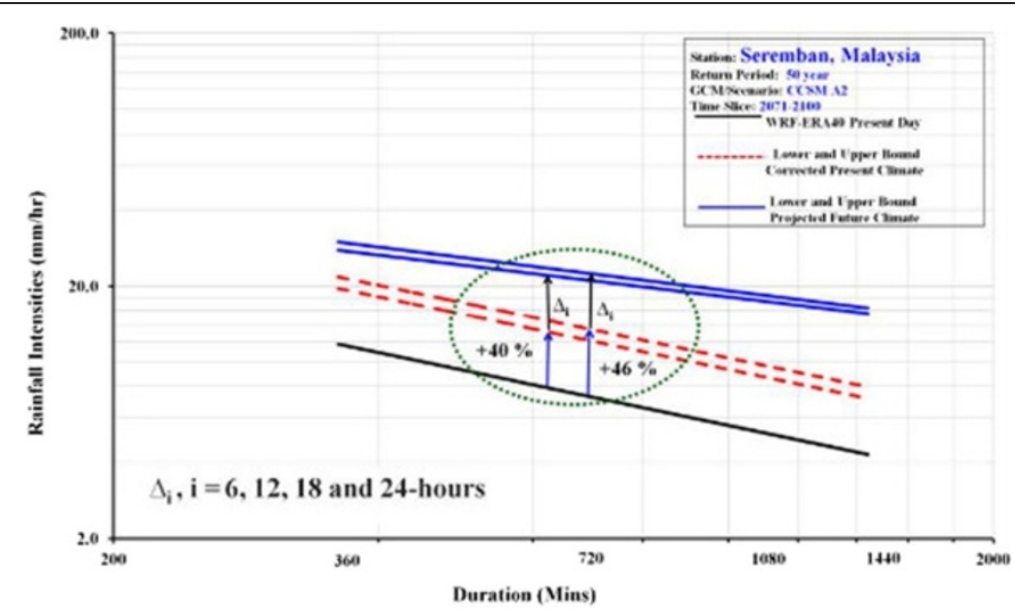

Figure 12 Projected future climate IDF curves (50-year return period, 2071-2100, WRF/CCSM A2 derived): Seremban station (within region). 


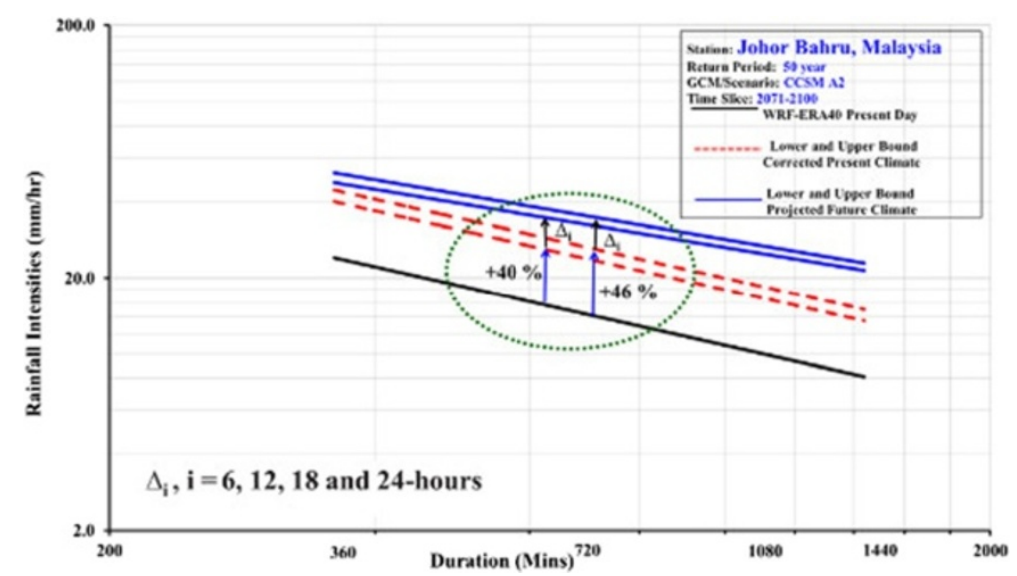

Figure 13 Projected future climate IDF curves (50-year return period, 2071-2100, WRF/CCSM A2 derived): Johor Bahru station (outside region).

dynamical downscaling using a regional climate model driven by Reanalysis data. In the paper, deriving future IDF curves for gauged and ungauged sites were also demonstrated; the climate change factor approach is adopted.

\section{Competing interests}

The authors declare that they have no competing interests.

\section{Authors' contributions}

$\mathrm{SCL}$ analysed data from the simulation model, interpretation of results and prepared the manuscript; SVR and SYL discussed analyses, interpretation, and presentation. All authors contributed extensively to the work presented in this paper. All authors discussed the results and implications and commented on the manuscript at all stages. All authors read and approved the final manuscript.

\section{Authors' information}

Dr Shie-Yui LIONG has been with Tropical Marine Science Institute of National University of Singapore (NUS) since 2004 after spending about 20 years with the Department of Civil and Environmental Engineering of NUS. He received his Dipl.-Ing. and Ph.D degrees from University of Karlsruhe (Germany) and lowa Institute of Hydraulics Research of University of lowa (USA) respectively. Dr. Liong's most recent research focus is on climate downscaling for Southeast Asia domain and deriving valuable information from the downscaled climate to evaluate the impacts of climate change on water resources, flooding, saltwater intrusion, crop yields, etc. He is also leading a team of researchers of different disciplines to develop an Eco-Hydraulics model for NeeSoon Swamp Forest.

He is currently an associate editor of Journal of Environmental Science and Policy (2011-present) and was an associate editor of Journal of Hydroinformatics (2004-2011). He was the President of Hydrological Science Section of AOGS (2008-2010), and Chairman of Joint IAHR-IWA-IAHS Hydroinfomatics Committee (2009-2012). Dr. Liong is a 3-time co-recipient of the Best Paper Award of IAHR-APD Congress (1994, 2002 and 2012). In 2007 he was awarded by the President of Federal Republic of Germany the Order of Merit ("Bundesverdienstkreuz"). He presented the Distinguished Lecture at the 10th Asia-Oceania Geosciences Society (AOGS) meeting in Brisbane in June 2013. Dr. Liew San Chuin has been with Tropical Marine Science Institute of National University of Singapore (NUS) since 2012. She received her PhD. degree from National University of Singapore (NUS) in 2013 and her B.Eng. (First Class Hons) from University of Science, USM (Malaysia). She was awarded NUS PhD. Research Scholarship. Prior to pursuing her PhD in 2008 she practiced as a consultant civil engineer in Malaysia.
Dr. Liew is the co-recipient of the Best Paper Award of IAHR-APD Congress (2012). In 2003, she was selected as the member of Outstanding Scholastic Achievement (awarded by Golden Key National Honour Society). She is currently a Research Fellow at the Tropical Marine Science Institute (TMSI) of the National University of Singapore. Her research topics focus on flood risks, climate change impacts and adaptation. She is interest to further her works into hydrology and economy impacts of climate change. Dr. V. Raghavan got his PhD from the University College London and has working at the Tropical Marine Science Institute of National University of Singapore since 2008. He has been actively involved in a number of climate change research projects. He is a Co-PI for some of the climate research projects and is also the Hydrological Sections of the AOGS and a volume editor for the "Advances in Geosciences" (HS), AOGS.

Dr. V. Raghavan is the co-recipient of the Best Paper Award of IAHR-APD Congress (2012) and the Best poster Award (AOGS 2013).

\section{Acknowledgements}

The resources provided by Tropical Marine Science Institute of National University of Singapore are especially acknowledged. We also received various supports from the Center for Hazards Research of Department of Civil and Environmental Engineering, Center for Environmental Sensing and Modeling (CENSAM). Their supports are sincerely acknowledged.

\section{Author details}

${ }^{1}$ Tropical Marine Science Institute, National University of Singapore, Singapore 119227, Singapore. ${ }^{2}$ Willis Research Network, Willis Re Inc., 51 Lime Street, London EC3M 7DQ, United Kingdom.

Received: 27 August 2013 Accepted: 1 March 2014 Published: 21 April 2014

\section{References}

1. Mikkelsen PS, Madsen H, Arnbjerg-Nielsen K, Jørgensen HK, Rosbjerg D, Harremoes P (1998) A rationale for using local and regional rainfall data for design and analysis of urban storm drainage systems. Water Sci Technol 37(11):7-14

2. Raiford JP, Aziz NM, Khan AA, Powell DN (2007) Rainfall depth-durationfrequency relationships for South Carolina, North Carolina, and Georgia. Am J Environ Sci 3(2):78-84

3. Mikkelsen PS, Madsen H, Arnbjerg-Nielsen K, Rosbjerg D, Harremoes P (2005) Selection of regional historical rainfall time series as input to urban drainage simulations at ungauged locations. Atmos Res 77:4-17

4. Nguyen VTV, Nguyen TD, Ashkar, F (2002) Regional frequency analysis of extreme rainfalls. Water Sci Technol 45(2): 75-81.

5. Lin GF, Wu MC (2007) A SOM-based approach to estimating design hyetographs of ungauged sites. J Hydrol 339(3-4):216-226 
6. Lin JY, Cheng CT, Sun YG, Chau KW (2005) Long-term prediction of discharges in Manwan Hydropower using Adaptive-Network-based Fuzzy Inference Systems Models. Lect Notes Comput Sci 3612:1152-1161

7. Chau KW, Wu CL, Li YS (2005) Comparison of several flood forecasting models in Yangtze River. J Hydrol Eng 10(6):485-491

8. Wu CL, Chau KW, Li YS (2009) Predicting monthly streamflow using data-driven models coupled with data-preprocessing techniques. Water Resour Res. 45(8):W08432. doi:10.1029/2007WR006737

9. El-Sayed EAH (2011) Generation of rainfall intensity duration frequency curves for ungauged sites. Nile Basin Water Sci Eng J 4(1):112-124

10. Liew SC, VRaghavan S, Liong S-Y (2013) How to construct future IDF curves, under changing climate, for sites with scarce rainfall records? Hydrol Process. 28(8):3276-3287

11. Uppala SM, Kållberg PW, Simmons AJ, Andrae U, da Costa BV, Fiorino M, Gibson JK, Haseler J, Hernandez A, Kelly GA, Li X, Onogi K, Saarinen S, Sokka N, Allan RP, Andersson E, Arpe K, Balmaseda MA, Beljaars ACM, van de Berg L, Bidlot J, Bormann N, Caires S, Chevallier F, Dethof A, Dragosavac M, Fisher M, Fuentes M, Hagemann S, Hólm E (2005) The ERA-40 reanalysis. Quart J R Meteorol Soc 131:2961-3012

12. Collins WD, Bitz CM, Blackmon ML, Bonan GB, Bretherton CS, Carton JA, Chang P, Doney SC, Hack JJ, Henderson TB, Kiehl JT, Large WG, McKenna DS, Santer BD, Smith RD (2006) The Community Climate System Model version 3 (CCSM3). J Clim 19:2122-2143

13. Hosking JR, Wallis JR (2005) Regional Frequency Analysis: An Approach Based on L-Moments. Cambridge University Press, Cambridge, UK

14. Wilby RL, Troni J, Biot Y, Tedd L, Hewitson BC, Smith DM, Sutton RT (2009) A review of climate risk information for adaptation and development planning. Int J Climatol 29:1196-1215

doi:10.1186/2196-4092-1-8

Cite this article as: Liew et al:: Development of Intensity-DurationFrequency curves at ungauged sites: risk management under changing climate. Geoscience Letters 2014 1:8.

\section{Submit your manuscript to a SpringerOpen ${ }^{\circ}$ journal and benefit from:}

- Convenient online submission

- Rigorous peer review

- Immediate publication on acceptance

- Open access: articles freely available online

- High visibility within the field

- Retaining the copyright to your article 